\title{
Obesity and chronic kidney disease: prevalence, mechanism, and management
}

Hyung Eun Yim, MD, PhD ${ }^{1}$, Kee Hwan Yoo, MD, PhD²

${ }^{1}$ Department of Pediatrics, Korea University Ansan Hospital, Korea University College of Medicine, Ansan, Korea; ${ }^{2}$ Department of Pediatrics, Korea University Guro Hospital, Korea University College of Medicine, Seoul, Korea

The prevalence of childhood obesity is increasing worldwide at an alarming rate. While obesity is known to increase a variety of cardiovascular and metabolic diseases, it also acts as a risk factor for the development and progression of chronic kidney disease (CKD). During childhood and adolescence, severe obesity is associated with an increased prevalence and incidence of the early stages of kidney disease. Importantly, children born to obese mothers are also at increased risk of developing obesity and CKD later in life. The potential mechanisms underlying the association between obesity and CKD include hemodynamic factors, metabolic effects, and lipid nephrotoxicity. Weight reduction via increased physical activity, caloric restriction, treatment with angiotensin-converting enzyme inhibitors, and judicious bariatric surgery can be used to control obesity and obesity-related kidney disease. Preventive strategies to halt the obesity epidemic in the healthcare community are needed to reduce the widespread deleterious consequences of obesity including CKD development and progression.

Key words: Fetal development, Intergenerational relations, Pediatric obesity, Proteinuria, Renal insufficiency

\footnotetext{
Key message

- Obesity is strongly associated with the development and progression of chronic kidney disease.

- Altered renal hemodynamics, metabolic effects, and lipid nephrotoxicity may play a key role in the development of obesityrelated kidney disease.

- Children born to obese mothers are at increased risk of developing obesity and chronic kidney disease later in life.

- A multilevel approach is needed to prevent obesity and related chronic diseases.
}

\section{Introduction}

Childhood obesity has been recognized as one of the most serious public health concerns worldwide. ${ }^{1)}$ Children with obesity often remain obese in adulthood and carry an increased risk of adverse clinical outcomes, including kidney disease. ${ }^{2-4)}$ Obesity is a key feature of metabolic syndrome, which is characterized by a group of cardiovascular risk factors, including central obesity, dyslipidemia, hypertension, and hyperglycemia. ${ }^{5}$ The prevalence of chronic kidney disease (CKD) is increasing concomitant with obesity. ${ }^{6)}$ The number of patients at all stages of CKD was approximately 700 million in 2017, and the age-standardized CKD mortality rate increased by $41.5 \%$ from 1990 to 2017.7$)$ The prevalence of $\mathrm{CKD}$ in the pediatric population has also increased steadily, and children and adolescents with CKD have a dramatically increased risk of death. ${ }^{8,9)}$ Obesity, diabetes mellitus (DM), and hypertension increase the risk of CKD. Obesity is strongly associated with the development and progression of CKD. ${ }^{5)}$ The prevalence of overweight and obesity among women of reproductive age is increasing rapidly, and evidence suggests that maternal obesity increases the risk of chronic diseases in offspring, including obesity and CKD. ${ }^{10-12)}$ Therefore, obesity is recognized by the pediatric nephrology community as a significant health challenge. ${ }^{13)}$ This review discusses the epidemiology of obesity, the effect of obesity on renal outcomes, the mechanisms of obesity in kidney disease, management of obesity-related kidney disease in children and adolescents, and evidence supporting the role of maternal obesity in the developmental programming of chronic diseases, especially CKD, in offspring.

\section{Epidemiology and definition of pediatric obesity}

Obesity in children of all ages has increased over the last 4 decades. Globally, the age-standardized prevalence of obesity from 1975 to 2016 increased from $0.9 \%$ to $7.8 \%$ among boys and from $0.7 \%$ to $5.6 \%$ among girls. ${ }^{14)}$ It is estimated that 38.2 million children aged $<5$ years were overweight or obese world. wide in 2019.1) Developing countries are undergoing a rapid epidemiological transition from normal weight to overweight and obesity, with rates similar to those observed in European countries and the United States many years ago. ${ }^{15)}$ Obesity in-

\footnotetext{
Corresponding author: Hyung Eun Yim, MD, PhD, Department of Pediatrics, Korea University Ansan Hospital, 123 Jeokgeum-ro, Danwon-gu, Ansan 15355, Korea \Email: he-yim@hanmail.net, https://orcid.org/0000-0001-9805-9278

Received: 29 January, 2021, Revised: 15 March, 2021, Accepted: 19 March, 2021

This is an open-access article distributed under the terms of the Creative Commons Attribution Non-Commercial License (http://creativecommons.org/licenses/bync/4.0/) which permits unrestricted non-commercial use, distribution, and reproduction in any medium, provided the original work is properly cited. Copyright (c) 2021 by The Korean Pediatric Society
} 
creases the risk of DM, cardiovascular disease (CVD), and CKD.

The definition of pediatric obesity based on high body mass index (BMI) in children depends on percentile cutoffs specific for age and gender. In children, overweight is defined as a BMI greater than or equal to the 85 th percentile and lower than the 95th percentile, and obesity is defined as a BMI greater than or equal to the 95 th percentile. ${ }^{16)}$ The American Heart Association defines severe obesity as a BMI $\geq 120 \%$ of the 95 th percentile or an absolute $\mathrm{BMI} \geq 35 \mathrm{~kg} / \mathrm{m}^{2}{ }^{17}$ ) Severe obesity in childhood and adolescence increases the risk of cardiovascular and metabolic disease in adulthood. ${ }^{18)}$

\section{The adverse effects of obesity on renal outcomes}

Obesity is an important predisposing factor for CKD and endstage renal disease (ESRD). ${ }^{19)}$ Wang et al. ${ }^{20}$ ) have shown that $24 \%-33 \%$ of all kidney disease cases in the United States are associated with obesity. Similarly, there is a link between obesity and the development and progression of CKD, and individuals with higher BMI carry a greater risk of developing proteinuria even without kidney disease. ${ }^{21,22)}$ Obesity predicts new-onset $\mathrm{CKD}$ and represents an independent risk factor for CKD progression regardless of underlying nephropathy. ${ }^{23-25)}$ Higher baseline BMI was an independent predictor of ESRD after adjusting for baseline comorbidities, such as hypertension and DM. ${ }^{25}$ ) Obesity in childhood and adolescence is associated with CKD and ESRD. ${ }^{19)}$ The prevalence of overweight and obesity in a pediatric population on renal replacement therapy in Europe was $20.8 \%$ and $12.5 \%$, respectively. ${ }^{26)}$ A long-term nationwide population-based study revealed that overweight and obesity in adolescents were strongly correlated with an increased risk of allcause ESRD. ${ }^{27)}$ In a study of 1.2 million adolescents followed for a mean of 25 years, obese adolescents aged 17 years showed a 3.4-fold higher risk of developing nondiabetic ESRD and a 19fold greater risk of developing diabetic ESRD, indicating a substantial association between elevated BMI in adolescence and diabetic and nondiabetic ESRD. ${ }^{27)}$

Obesity is related to a secondary form of focal segmental glomerulosclerosis (FSGS) known as obesity-related glomerulopathy (ORG). The incidence of ORG has increased worldwide in parallel with the increase in the prevalence of obesity. In a 15year study, Kambham et al. ${ }^{28)}$ reported that the incidence of ORG in native kidney biopsies increased 10 -fold, from $0.2 \%$ in 1986-1990 to 2.0\% in 1996-2000. In this series, 56\% of obese patients had proteinuria, and 44\% showed proteinuria and renal insufficiency. Histologically, the perihilar variant of FSGS is predominantly associated with ORG, and podocyte foot process effacement in ORG is less severe than that in primary FSGS. ${ }^{29,30)}$ Although some patients show nephrotic-range proteinuria and the progressive deterioration of renal function, ${ }^{29)}$ the most frequent clinical manifestation of ORG is subnephrotic proteinuria. The limited presence of full nephrotic syndrome in patients with
ORG can be clinically significant since a progressive increase in proteinuria may go unnoticed for years, leading to late diagnosis of renal failure. ${ }^{29)}$ Many studies suggest that obesity-associated insulin resistance increases the risk of $\mathrm{CKD}$ progression following a period of "silent" glomerular hyperfiltration. ${ }^{31,32)}$ Obesity is significantly related to the development and progression of renal diseases other than ORG. ${ }^{29,33-38)}$ In patients with immunoglobulin A nephropathy, hypertension, proteinuria $\geq 1 \mathrm{~g} /$ day, and severe histopathological lesions at diagnosis were more frequent in the overweight and obese groups. ${ }^{33)}$ Overweight and obesity increased the risk of interstitial fibrosis in patients with IgA nephropathy, suggesting a connection between BMI and IgA nephropathy progression. ${ }^{34)}$ In a pediatric cohort with proteinuric kidney diseases, the glomerular volume was larger in obese children than in nonobese children with FSGS. ${ }^{35)}$ In this cohort, obese children born preterm carried a 2-fold higher risk of developing ESRD than obese patients born at term and a 5 -fold greater risk of prog. ressing to ESRD than nonobese preterm children. ${ }^{36}$ )

Other complications of obesity include nephrolithiasis and kidney malignancies. BMI, waist circumference, and weight were positively associated with the development of incident kidney stones. ${ }^{39)}$ In a retrospective review of 1,698 stone-forming patients, urinary calcium, oxalate, and urate excretion were much higher in overweight and obese patients than in nonobese patients. ${ }^{40)}$ Higher BMI showed a positive correlation with risk factors for kidney stones, including increased urine sodium and decreased $\mathrm{pH}$ in men and increased urine uric acid and sodium and decreased urine citrate in women. ${ }^{41)}$ Additionally, overweight and obesity increase the risk of renal cancer. Renal cancer is the third highest risk associated with obesity among all cancers. ${ }^{42)}$ In a population-based cohort study of 5.24 million adults in the United Kingdom, each $1-\mathrm{kg} / \mathrm{m}^{2}$ population-wide increase in BMI was estimated to result in 3,790 additional cases of 1 of 10 cancers (colon, liver, gall bladder, breast, cervix, uterus, ovaries, kidney, thyroid, and leukemia) annually. ${ }^{43)}$ In particular, the risk of kidney cancer in adults with a 5 -fold higher BMI increased by $25 \%$, and excess weight contributed to $10 \%$ of all kidney cancers. ${ }^{43)}$ A recent cohort study of 23.3 million East Asians revealed that the coexistence of general and abdominal obesity increased the risk of kidney cancer by nearly 1.5 -fold, compared with nonobese individuals. ${ }^{44)}$ Table 1 summarizes the renal complications of obesity.

\section{Mechanisms of obesity in kidney disease}

The exact mechanisms underlying the association between obesity and CKD remain unclear. A combination of hemodynamic and metabolic changes and lipid nephrotoxicity (excessive lipid deposition) may cause or aggravate CKD in obese individuals (Table 2).

\section{Hemodynamic factors}

Renal physiologic response to obesity is mediated via an in- 
Table 1. Adverse renal consequences of obesity

\begin{tabular}{|c|c|c|c|c|c|}
\hline Study & $\begin{array}{l}\text { Sample } \\
\text { size }\end{array}$ & $\begin{array}{l}\text { Age } \\
(y r)\end{array}$ & $\begin{array}{l}\text { Follow-up } \\
\text { (yr) }\end{array}$ & Outcomes & Main findings \\
\hline Garofalo et al. ${ }^{21)}$ & 630,677 & $>18$ & 6.8 & $\begin{array}{l}\text { Albuminuria, eGFR }<60 \\
\mathrm{~mL} / \mathrm{min} / 1.73 \mathrm{~m}^{2}, \text { CKD }\end{array}$ & $\begin{array}{l}\text { Obesity acts as independent predictor of new-onset CKD; risk of } \\
\text { new-onset low eGFR and albuminuria increased by } 28 \% \text { and } 51 \% \\
\text { in obese subjects. }\end{array}$ \\
\hline Chang et al. ${ }^{22)}$ & 2,354 & $28-40$ & 15 & $\begin{array}{l}\text { Incident micro- } \\
\text { albuminuria }\end{array}$ & $\begin{array}{l}\text { Obesity was associated with incident microalbuminuria (OR, 1.9; } \\
95 \% \mathrm{Cl}, 1.1-3.3) \text {. }\end{array}$ \\
\hline Tsujimoto et al. ${ }^{23)}$ & 105,611 & $40-79$ & 5 & CKD & $\begin{array}{l}\text { The risk of stage } \geq 3 \text { CKD was markedly higher among men and } \\
\text { older women. }\end{array}$ \\
\hline Hsu et al. ${ }^{25)}$ & 320,252 & $>18$ & $15-35$ & ESRD & $\begin{array}{l}\text { Linearly higher risk of ESRD was observed across increasing BMI } \\
\text { categories. }\end{array}$ \\
\hline Vivante et al. ${ }^{27)}$ & $1,194,704$ & 17 & 25 & Incident ESRD & $\begin{array}{l}\text { Overweight and obesity at age } 17 \text { years were strongly associated } \\
\text { with increased risk for all-cause treated ESRD later in life. }\end{array}$ \\
\hline Kambham et al. ${ }^{28)}$ & 6,818 & $8-71$ & 15 & ORG & $\begin{array}{l}\text { Review of native renal biopsies revealed a } 10 \text {-fold increased } \\
\text { incidence of ORG from 0.2\% in 1986-1990 to } 2.0 \% \text { in } 1996-2000 .\end{array}$ \\
\hline Berthoux et al. ${ }^{33)}$ & 331 & 40.9 & 9.2 & CKD, dialysis/death & $\begin{array}{l}\text { In the overweight/obese IgA nephropathy patient group, the final } \\
\text { outcome was worse: greater prevalence of } \geq 3 \text { CKD ( } 43.4 \text { vs. } \\
21.0 \% \text { ) and dialysis/death ( } 21.3 \text { vs. } 13.9 \% \text { ). }\end{array}$ \\
\hline Taylor et al. ${ }^{39)}$ & 4,827 & $27-75$ & 46 & Kidney stone & $\begin{array}{l}\text { Obesity was associated with the risk of kidney stone formation, and } \\
\text { this association was more obvious in women than in men. }\end{array}$ \\
\hline Bhaskaran et al. ${ }^{43)}$ & $5,243,978$ & $\geq 16$ & 7.5 & Kidney cancer & $\begin{array}{l}\text { Each } 5-\mathrm{kg} / \mathrm{m}^{2} \text { increase in } \mathrm{BMI} \text { was linearly associated with kidney } \\
\text { cancer }(\mathrm{OR}, 1.25 ; 95 \% \mathrm{Cl}, 1.17-1.33)\end{array}$ \\
\hline Nam et al. ${ }^{44)}$ & $23,313,046$ & $\geq 20$ & 5.4 & Kidney cancer & $\begin{array}{l}\text { Positive linear associations were observed between } \mathrm{BMI} \text { and waist } \\
\text { circumference, and the risk of incident kidney cancer. }\end{array}$ \\
\hline
\end{tabular}

eGFR, estimated glomerular filtration rate; CKD, chronic kidney disease; OR, odds ratio; $\mathrm{Cl}$, confidence interval; ESRD, end-stage renal disease; ORG, obesityrelated glomerulopathy; $\mathrm{BMI}$, body mass index.

crease in renal plasma flow, glomerular filtration rate (GFR), filtration fraction, and proximal tubular reabsorption of sodium. 29) Studies on renal hemodynamics have revealed that higher $\mathrm{BMI}$ is associated with a greater increase in GFR relative to renal plasma flow and, consequently, a higher filtration fraction. ${ }^{45)}$ It remains unclear whether elevated GFR at the whole-kidney level reflects glomerular hyperfiltration at the single-nephron level. ${ }^{46)}$ Nonetheless, it has been hypothesized that glomerular hyperfiltration is a major link between obesity and renal injury. ${ }^{47}$ Although the exact concept of glomerular hyperfiltration is uncertain, 2 main mechanisms have been proposed to explain obesity-related renal disease. The first hypothesis proposes that afferent arteriolar vasodilation is the primary event in glomerular hyperfiltration. ${ }^{48)}$ The vasodilation of renal afferent arterioles and efferent arteriole constriction increase renal plasma flow, glomerular hydrostatic pressure, and single-nephron filtration rate. ${ }^{29)}$ The second hypothesis states that the increase in the proximal tubular reabsorption of sodium and water is the main contributor to decreased sodium delivery to the macula densa, deactivation of the tubuloglomerular feedback, afferent arteriolar vasodilation, and subsequent glomerular hyperfiltration. ${ }^{49,50)}$ The increased activation of sodium transporters in the nephron may be involved in increased tubular sodium reabsorption in the kidney of obese patients. ${ }^{51)}$ In glomerular hyperfiltration, podocytes are exposed to high fluid shear stress, which results in maladaptive podocyte hypertrophy, podocyte detachment, and global glomerulosclerosis. ${ }^{29)}$ Furthermore, elevated sympathetic activity and the upregulation of the renin-angiotensin-aldosterone system in obese individuals may play an important role in glomerular hyperfiltration by increasing sodium retention and
Table 2. Potential mechanisms underlying the association between obesity and CKD

\begin{tabular}{|c|c|}
\hline Factor & Renal alterations by obesity \\
\hline \multirow[t]{6}{*}{ Hemodynamic factors } & Glomerular hyperfiltration $45-48)$ \\
\hline & Increased podocyte injury ${ }^{29)}$ \\
\hline & Glomerulomegaly \& glomerulosclerosis ${ }^{29)}$ \\
\hline & Excessive tubular sodium reabsorption ${ }^{49-51)}$ \\
\hline & Increased sympathetic activity ${ }^{29)}$ \\
\hline & Increased RAAS activity ${ }^{47,51)}$ \\
\hline \multirow[t]{5}{*}{ Metabolic effects } & Abnormal lipid metabolism²,53,73) \\
\hline & Adipokine dysregulation ${ }^{54-64,66-69)}$ \\
\hline & Increased insulin resistance ${ }^{64,65)}$ \\
\hline & Increased inflammation ${ }^{70,71,73)}$ \\
\hline & Increased oxidative stress $s^{73,74)}$ \\
\hline \multirow[t]{4}{*}{ Lipid nephrotoxicity } & Excessive renal fat accumulation ${ }^{70-72)}$ \\
\hline & Glomerular and tubular cell injuries ${ }^{71-73)}$ \\
\hline & $\begin{array}{l}\text { Mitochondrial dysfunction, oxidative stress \& } \\
\text { inflammation } 71,73,74)\end{array}$ \\
\hline & $\underset{73,74)}{\text { Increased FFA toxicity to proximal tubular cells }}$ \\
\hline
\end{tabular}

CKD, chronic kidney disease; RAAS, renin-angiotensin-aldosterone system; FFA, free fatty acid.

hypertension. ${ }^{29)}$

\section{Metabolic effects}

Obesity leads to metabolic abnormalities. Changes in lipid and lipoprotein metabolism result in dyslipidemia, which contributes to the development and progression of renal disease. Nevertheless, most people who are overweight and obese do not develop $\mathrm{CKD}$, and up to $25 \%$ of obese individuals are metabolically 
healthy, suggesting that weight gain alone may not be enough to trigger the development of kidney diseases. ${ }^{52)}$ As an endocrine organ, the adipose tissue secretes adipokines, and the altered production of adipokines contributes to complications in obesity. ${ }^{53)}$ Adipokines are cytokines involved in lipid metabolism, inflammation, immune response, insulin resistance, atherosclerosis, metabolic homeostasis, and cell migration and proliferation. ${ }^{54)}$ These cytokines induce adaptive or maladaptive responses in renal cells against the mechanical forces of glomerular hyperfiltration. ${ }^{53)}$ Many adipokines, including leptin, adiponectin, vascular endothelial growth factor, angiopoietins, and resistin, play a role in extracellular matrix accumulation, leading to renal fibrosis. ${ }^{55)}$

The serum levels of the proinflammatory adipokine leptin are approximately $5-10$-fold higher in obese individuals than in nonobese individuals. ${ }^{56}$ In addition to the control of appetite, energy expenditure, and body weight, leptin affects the immune system and may exacerbate renal dysfunction. ${ }^{57}$ Leptin is mainly metabolized in the kidneys by binding to the multiligand endocytic receptor megalin in the proximal tubule. ${ }^{58)}$ Leptin induces glomerular hypertrophy by stimulating glomerular endothelial and mesangial cell proliferation and directly affects kidney function. ${ }^{59,60)}$ Additionally, leptin levels are strongly correlated with inflammation and insulin resistance, which are risk factors for the development of CKD. ${ }^{61,62)}$

The anti-inflammatory adiponectin protects against obesityassociated metabolic complications, including insulin resistance and lipid accumulation. ${ }^{63)}$ Circulating adiponectin levels are negatively linked with percent body fat, suggesting an inverse correlation between adiponectin and obesity. ${ }^{64,65)}$ Furthermore, low levels of plasma adiponectin are inversely correlated with proteinuria in obese subjects and can predict adverse renal outcomes in patients with type 2 DM. ${ }^{66,67)}$ Experimental studies suggest that adiponectin directly affects podocyte function and reduces oxidative stress, decreasing albuminuria. ${ }^{68)}$ Adiponectin can be a predictor of CKD, and circulating adiponectin levels are negatively linked with estimated GFR. ${ }^{69}$

\section{Lipid nephrotoxicity}

Dysregulated fatty acid and cholesterol metabolism in obesity leads to lipid accumulation, oxidative stress, inflammation, and fibrosis. ${ }^{29)}$ Fat accumulation in the kidneys causes structural and functional changes in glomerular and tubular epithelial cells, leading to the development of $\mathrm{ORG}{ }^{70)}$ Increased triglyceride accumulation in the kidneys was associated with cortical microvascular proliferation, glomerular hyperfiltration, increased proangiogenic and proinflammatory cytokines, and albumin leakage. 71) Notably, the presence of secondary FSGS and glomerulomegaly was related to serum triglycerides and renal lipid deposition but not to the degree of obesity. ${ }^{72}$ The increased production of reactive oxygen species and lipid peroxidation, mitochondrial dysfunction, and tissue inflammation are important mechanisms underlying damage to podocytes, proximal tubular epithelial cells, and tubulointerstitial tissue by excessive free fatty acids, resulting in glomerular and tubular lesions. ${ }^{73)}$ In particular, renal proximal tubular cells are known to be more vulnerable to lipid toxicity than other renal cell populations because of higher energy expenditure, which is exclusively mediated via mitochondrial oxidative phosphorylation. ${ }^{73,74)}$

\section{Developmental programming of obesity and CKD}

In the 1980s, Barker et al. ${ }^{75)}$ first proposed the fetal origins hypothesis to explain the connection between fetal growth and cardiovascular morbidity. These authors reported that maternal undernutrition during gestation increased the risk of CVD in the offspring later in life. Later studies confirmed the relationship between birth weight and the risk of type $2 \mathrm{DM}$, hypertension, CVD, and CKD. ${ }^{76-78)}$ Experimental and clinical studies suggest that maternal obesity increases the risk of premature death and cardiovascular and chronic diseases in the offspring, including obesity, hyperglycemia, and DM..$^{10,11)}$ Alterations in macronutrient availability, epigenetic modifications, dysregulated adipokine production, and inflammation are the primary mechanisms underlying developmental programming of obesity. ${ }^{79)}$ Emerging evidence suggests that fetal exposure to maternal obesity increases the risk of developing CKD later in life, indicating that intrauterine exposure to maternal obesity is a significant risk factor for CKD. ${ }^{12)}$ In rodent models of maternal obesity, offspring of obese mothers had albuminuria, renal pathology, increased fat deposition, impaired glucose tolerance, and insulin resistance. ${ }^{12}$, ${ }^{80,81)}$ The renal effects of maternal obesity related to oxidative stress, inflammation, and fibrosis persisted until adolescence in the offspring of obese mothers. ${ }^{12)}$ In addition, clinical studies have demonstrated that maternal DM or obesity predisposes offspring to hypertension, renal hyperfiltration, and $\mathrm{CKD} .{ }^{82,83)}$ A population-based study involving 1,994 children with CKD found that low birth weight, pregestational and gestational DM, and maternal overweight and obesity increased the risk of child. hood CK.D ${ }^{83)}$ Exposure to maternal overweight and obesity increased the risk of CKD by $24 \%$ and 26\%, respectively, compared with controls. ${ }^{83)}$ Obese mothers, independent of the presence of DM, showed a higher risk of bearing children with CKD due to obstructive uropathy than nonobese mothers. ${ }^{83)}$ These findings imply that maternal obesity impairs renal development and increases the risk of CKD in offspring. ${ }^{84)}$ Potential mechanisms underlying this effect include autophagy, inflammation, oxidative stress, and epigenetic regulation. ${ }^{85)}$ Environmental factors aggravate renal damage in offspring born to obese mothers. Obesity and other comorbid conditions in offspring exacerbate the deleterious effects of maternal obesity on children's kidney health ${ }^{85)}$ Early life risk factors, such as intrauterine growth restriction, low and high birth weight, low nephron number, drug use, and rapid postnatal growth, are also linked to developmental programming of renal function (Fig. 1). ${ }^{86,87}$ ) 


\section{Management}

While genetic, metabolic, and environmental factors are implicated in the development of obesity, obesity may be a modifiable lifestyle risk factor for the progression of CKD. Hence, weight reduction through dietary management and increased physical activity remain the cornerstone of obesity treatment. ${ }^{88)}$ In overweight or obese people with type $2 \mathrm{DM}$, intensive lifestyle interventions diminished the risk of CKD by $31 \%$ compared with DM management and education. ${ }^{89)}$ A systematic review involving obese patients with altered renal function demonstrated that intentional weight loss consistently decreased blood pressure, hyperfiltration, and proteinuria. ${ }^{90)}$ Physical exercise combined with optimization of the metabolic and nutritional status is crucial in the management of patients with CKD. ${ }^{91)}$ In addition, treatment with angiotensin-converting enzyme inhibitors decreases proteinuria and the risk of renal disease progression in obese individuals. ${ }^{88,92)}$ The renoprotective effect of these drugs in proteinuric patients with CKD was more pronounced in obese patients with CKD than in overweight or normal BMI patients. ${ }^{92)}$ Dyslipidemia treatment together with the limited intake of saturated fat and cholesterol is also important in children with CKD ${ }^{88)}$ However, treating children and adolescents with lipidlowering drugs is controversial: some guidelines do not advocate the use of statins in children with CKD, and other guidelines recommend statins to children aged 10-21 years with continuously increased levels of low-density lipoprotein cholesterol after dietary management for 6 months. ${ }^{93,94)}$ Notably, bariatric surgery has been performed in severely obese patients (BMI $\geq 35 \mathrm{~kg} / \mathrm{m}^{2}$ ) and significantly improved GFR in patients with advanced CKD for up to 3 years. ${ }^{95,96)}$ Evidence-based best practice guidelines recommend weight loss surgery for adolescents with extreme obesity and other severe comorbidities. ${ }^{97)}$ In severely obese adolescents with decreased renal function at baseline, the mean estimated GFR following bariatric surgery increased from 76 to $102 \mathrm{~mL} / \mathrm{min} / 1.73 \mathrm{~m}^{2}$ at 3-year follow-up. ${ }^{98)}$ Albuminuria significantly improved after surgery in patients with increased albuminuria at baseline. ${ }^{98)}$ Long-term cohort studies and randomized clinical trials reported that bariatric surgery prevented the development and progression of CKD and improved weight reduction, blood pressure, and metabolic control. ${ }^{99)}$ Pharmacotherapy can be used as a component of a comprehensive strategy for managing patients with severe obesity and obesity-related comorbidities. However, the effectiveness of this therapy for obesity-related comorbidities are limited. ${ }^{6,100)}$ The major antiobesity medications approved by the U.S. Food and Drug Administration include orlistat (pancreatic and gastric lipase inhibitor), phentermine (sympathomimetic amine), lorcaserin (selective serotonin receptor agonist), phentermine/topiramate (sympathomimetic amine anorectic agent/antiepileptic drug), naltrexone/bupropion (opioid antagonist/aminoketone antidepressant), and liraglutide (a glucagon-like peptide 1 receptor agonist). ${ }^{100)}$ Orlistat and phentermine are approved for treating obesity in adolescents. ${ }^{101)}$ Orlistat can be prescribed to adolescents aged $\geq 12$ years for long-term management of obesity. This drug reduces fatty acid absorption by the intestinal endothelium through inhibiting gastrointestinal and pancreatic lipases. ${ }^{102)}$ Phentermine is an amphetamine analog that can be prescribed to adolescents aged $>16$ years for short-term treatment of obesity. 101) This drug works as an appetite suppressant by increasing catecholamine and serotonin activity in the central nervous system. 100,101) However, evidence to support the use of antiobesity drugs in children and adolescents is currently limited, and a multilevel approach is needed to prevent obesity and related chronic diseases. Early lifestyle interventions, including exercise and dietary changes, should be the first-line approach for preventing and

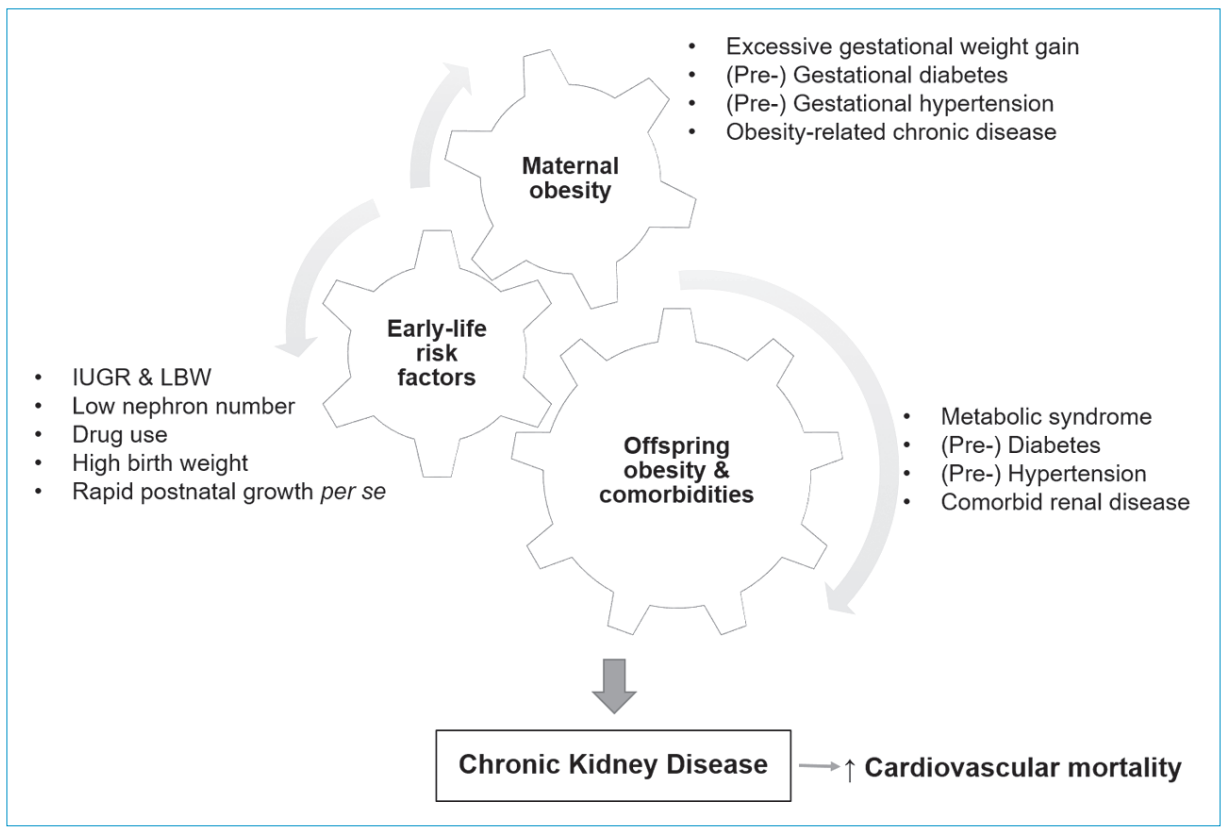

Fig. 1. Developmental programming of chronic kidney disease. IUGR, intrauterine growth restriction; LBW, low birth weight. 
treating obesity.

\section{Conclusion}

Obesity is strongly associated with the development and prog. ression of kidney diseases. Obesity increases the risk of CKD, hypertension, and DM in children and adolescents and the risk of mortality in children with ESRD. Maternal obesity predisposes offspring to CKD and obesity, indicating that intrauterine exposure to maternal obesity is an important risk factor for developing CKD. Therefore, pediatricians should acknowledge the long-term effects of maternal obesity on renal outcomes in children. Weight loss due to increased physical activity and caloric restriction should be considered the first-line therapy for treating obesity in children and adolescents. Lifestyle modifications can improve several risk factors simultaneously and reduce the risk of CKD. The development of evidence-based interventions is necessary to halt the intergenerational transmission of obesity and related chronic diseases.

\section{Footnotes}

Conflicts of interest: No potential conflict of interest relevant to this article was reported.

\section{ORCID:}

Hyung Eun Yim (1) https://orcid.org/0000-0001-9805-9278

Kee Hwan Yoo (1) https://orcid.org/0000-0001-6490-4293

\section{References}

1. World Health Organization. Obesity and overweight [Internet]. Geneva (Switzerland): World Health Organization; 2020 [cited 2020 Apr 1]. Available from: https:/www.who.int/news-room/fact-sheets/detail/obesityand-overweight.

2. Maring B, Greenspan LC, Chandra M, Daniels SR, Sinaiko A, Prineas RJ, et al. Comparing US paediatric and adult weight classification at the transition from late teenage to young adulthood. Pediatr Obes 2015;10: 371-9.

3. Umer A, Kelley GA, Cottrell LE, Giacobbi P Jr, Innes KE, Lilly CL. Childhood obesity and adult cardiovascular disease risk factors: a systematic review with meta-analysis. BMC Public Health 2017;17:683.

4. Lalan S, Jiang S, Ng DK, Kupferman F, Warady BA, Furth S, et al. Cardiometabolic risk factors, metabolic syndrome, and chronic kidney disease progression in children. J Pediatr 2018;202:163-70.

5. Gepstein V, Weiss R. Obesity as the main risk factor for metabolic syndrome in children. Front Endocrinol 2019;10:568.

6. Câmara NO, Iseki K, Kramer H, Liu ZH, Sharma K. Kidney disease and obesity: epidemiology, mechanisms and treatment. Nat Rev Nephrol 2017;13:181-90

7. GBD Chronic Kidney Disease Collaboration. Global, regional, and national burden of chronic kidney disease, 1990-2017: a systematic analysis for the global burden of disease study 2017. Lancet 2020;395:709-33.

8. Chong LSH, Sautenet B, Tong A, Hanson CS, Samuel S, Zappitelli M, et al. Range and heterogeneity of outcomes in randomized trials of pediatric chronic kidney disease. J Pediatr 2017;186:110-17.e11.

9. Chou HH, Chiou YY, Chiou YH, Tain YL, Wang HH, Yu MC, et al. Mortality risks among various primary renal diseases in children and adolescents on chronic dialysis. J Clin Med 2018;7:414.

10. Rodríguez-González GL, Reyes-Castro LA, Bautista CJ, Beltrán AA, Ibáñez CA, Vega CC, et al. Maternal obesity accelerates rat offspring metabolic ageing in a sex-dependent manner. J Physiol 2019;597:5549-63.

11. Lee KK, Raja EA, Lee AJ, Bhattacharya S, Bhattacharya S, Norman JE, et al. Maternal obesity during pregnancy associates with premature mortality and major cardiovascular events in later life. Hypertension 2015;66: 938-44.

12. Glastras SJ, Chen H, Tsang M, Teh R, McGrath RT, Zaky A, et al. The renal consequences of maternal obesity in offspring are overwhelmed by postnatal high fat diet. PLoS One 2017;12:e0172644.

13. Correia-Costa L, Azevedo A, Caldas Afonso A. Childhood obesity and impact on the kidney. Nephron 2019;143:8-11.

14. NCD Risk Factor Collaboration (NCD-RisC). Worldwide trends in bodymass index, underweight, overweight, and obesity from 1975 to 2016: a pooled analysis of 2416 population-based measurement studies in 128.9 million children, adolescents, and adults. Lancet 2017;390:2627-42.

15. Templin T, Cravo Oliveira Hashiguchi T, Thomson B, Dieleman J, Bendavid E. The overweight and obesity transition from the wealthy to the poor in low- and middle-income countries: a survey of household data from 103 countries. PLoS Med 2019;16:e1002968.

16. Barlow SE, Expert C. Expert committee recommendations regarding the prevention, assessment, and treatment of child and adolescent overweight and obesity: summary report. Pediatrics 2007;120:S164-92.

17. Kelly AS, Barlow SE, Rao G, Inge TH, Hayman LL, Steinberger J, et al. Severe obesity in children and adolescents: identification, associated health risks, and treatment approaches: a scientific statement from the American Heart Association. Circulation 2013;128:1689-712.

18. Bendor CD, Bardugo A, Pinhas-Hamiel O, Afek A, Twig G. Cardiovascular morbidity, diabetes and cancer risk among children and adolescents with severe obesity. Cardiovasc Diabetol 2020;19:79.

19. Assadi F. The growing epidemic of chronic kidney disease: preventive strategies to delay the risk for progression to ESRD. Adv Exp Med Biol 2019;1121:57-9.

20. Wang Y, Chen X, Song Y, Caballero B, Cheskin LJ. Association between obesity and kidney disease: a systematic review and meta-analysis. Kidney Int 2008;73:19-33.

21. Garofalo C, Borrelli S, Minutolo R, Chiodini P, De Nicola L, Conte G. A systematic review and meta-analysis suggests obesity predicts onset of chronic kidney disease in the general population. Kidney Int 2017;91: 1224-35.

22. Chang A, Van HL, Jacobs DR Jr, Liu K, Muntner P, Newsome B, et al. Lifestyle-related factors, obesity, and incident microalbuminuria: the CARDIA (Coronary Artery Risk Development in Young Adults) study. Am J Kidney Dis 2013;62:267-75.

23. Tsujimoto T, Sairenchi T, Iso H, Irie F, Yamagishi K, Watanabe H, et al. The dose-response relationship between body mass index and the risk of incident stage $\geq 3$ chronic kidney disease in a general Japanese population: the Ibaraki prefectural health study (IPHS). J Epidemiol 2014;24:444-51.

24. Ladhani M, Craig JC, Irving M, Clayton PA, Wong G. Obesity and the risk of cardiovascular and all-cause mortality in chronic kidney disease: a systematic review and meta-analysis. Nephrol Dial Transplant 2017;32: 439-49.

25. Hsu CY, McCulloch CE, Iribarren C, Darbinian J, Go AS. Body mass index and risk for end-stage renal disease. Ann Intern Med 2006;144:21-8.

26. Bonthuis M, van Stralen KJ, Verrina E, Groothoff JW, Alonso Melgar Á, Edefonti A, et al. Underweight, overweight and obesity in paediatric dialysis and renal transplant patients. Nephrol Dial Transpl 2013;28:195204.

27. Vivante A, Golan E, Tzur D, Leiba A, Tirosh A, Skorecki K, et al. Body mass index in 1.2 million adolescents and risk for end-stage renal disease. Arch Intern Med 2012;172:1644-50.

28. Kambham N, Markowitz G, Valeri A, Lin J, D'Agati VD. Obesity-related glomerulopathy: an emerging epidemic. Kidney Int 2001;59:1498-509. 
29. D'Agati VD, Chagnac A, de Vries AP, Levi M, Porrini E, Herman-Edelstein $\mathrm{M}$, et al. Obesity-related glomerulopathy: clinical and pathologic characteristics and pathogenesis. Nat Rev Nephrol 2016;12:453-71.

30. Xu T, Sheng Z, Yao L. Obesity-related glomerulopathy: pathogenesis, pathologic, clinical characteristics and treatment. Front Med 2017;11:3408.

31. Hong S, Choi YM, Ihm SH, Kim D, Choi MG, Yu JM, et al. Association between metabolic parameters and glomerular hyperfiltration in a representative Korean population without chronic kidney disease. PLoS One 2018;13:e0207843.

32. Yang S, Cao C, Deng T, Zhou Z. Obesity-related glomerulopathy: a latent change in obesity requiring more attention. Kidney Blood Press Res 2020; 45:510-22.

33. Berthoux F, Mariat C, Maillard N. Overweight/obesity revisited as a predictive risk factor in primary IgA nephropathy. Nephrol Dial Transplant 2013;28 Suppl 4:iv160-6.

34. Wu C, Wang AY, Li G, Wang L. Association of high body mass index with development of interstitial fibrosis in patients with IgA nephropathy. BMC Nephrol 2018;19:381.

35. Abitbol CL, Chandar J, Rodríguez MM, Berho M, Seeherunvong W, Freundlich $\mathrm{M}$, et al. Obesity and preterm birth: additive risks in the prog. ression of kidney disease in children. Pediatr Nephrol 2009;24:1363-70.

36. Kim JY, Cho H. Effect of hypertension on childhood-onset systemic lupus erythematous in a tertiary medical center in Korea. Child Kidney Dis 2020;24:107-14.

37. Lee MJ, Yim HE, Yoo KH. A case of renal cortical necrosis in a 15-year-old boy with acute kidney injury. Child Kidney Dis 2019;23:53-7.

38. Yim HE, Han KD, Kim B, Yoo KH. Impact of early-life weight status on urinary tract infections in children: a nationwide population-based study in Korea. Epidemiol Health 2021;43:e2021005.

39. Taylor EN, Stampfer MJ, Curhan GC. Obesity, weight gain, and the risk of kidney stones. JAMA 2005;293:455-62.

40. Trinchieri A, Croppi E, Montanari E. Obesity and urolithiasis: evidence of regional influences. Urolithiasis 2017;45:271-8.

41. Eisner BH, Eisenberg ML, Stoller ML. Relationship between body mass index and quantitative 24-hour urine chemistries in patients with nephrolithiasis. Urology 2010;75:1289-93.

42. Renehan AG, Tyson M, Egger M, Heller RF, Zwahlen M. Body-mass index and incidence of cancer: a systematic review and meta-analysis of prospective observational studies. Lancet 2008;371:569-78.

43. Bhaskaran K, Douglas I, Forbes H, dos-Santos-Silva I, Leon DA, Smeeth L. Body-mass index and risk of 22 specific cancers: a population-based cohort study of 5.24 million UK adults. Lancet 2014;384:755-65.

44. Nam GE, Cho KH, Han K, Kim CM, Han B, Cho SJ, et al. Obesity, abdominal obesity and subsequent risk of kidney cancer: a cohort study of 23.3 million East Asians. Br J Cancer 2019;121:271-7.

45. Kwakernaak AJ, Toering TJ, Navis G. Body mass index and body fat distribution as renal risk factors: a focus on the role of renal haemodynamics. Nephrol Dial Transplant 2013;28 Suppl 4:iv42-9.

46. Helal I, Fick-Brosnahan GM, Reed-Gitomer B, Schrier RW. Glomerular hyperfiltration: definitions, mechanisms and clinical implications. Nat Rev Nephrol 2012;8:293-300.

47. Chagnac A, Zingerman B, Rozen-Zvi B, Herman-Edelstein M. Consequences of glomerular hyperfiltration: the role of physical forces in the pathogenesis of chronic kidney disease in diabetes and obesity. Nephron 2019;143:38-42.

48. Brenner BM, Lawler EV, Mackenzie HS. The hyperfiltration theory: a paradigm shift in nephrology. Kidney Int 1996;49:1774-7.

49. Hallow KM, Gebremichael Y, Helmlinger G, Vallon V. Primary proximal tubule hyperreabsorption and impaired tubular transport counterregulation determine glomerular hyperfiltration in diabetes: a modeling analysis. Am J Physiol Renal Physiol 2017;312:F819-35.

50. Vallon V, Thomson SC. The tubular hypothesis of nephron filtration and diabetic kidney disease. Nat Rev Nephrol 2020;16:317-36.

51. Shah S, Hussain T. Enhanced angiotensin II-induced activation of $\mathrm{Na}+$, $\mathrm{K}+$-ATPase in the proximal tubules of obese Zucker rats. Clin Exp Hypertens 2006;28:29-40
52. Bluher M. The distinction of metabolically "healthy" from "unhealthy" obese individuals. Curr Opin Lipidol 2010;21:38-43.

53. Xiao Y, Liu D, Cline MA, Gilbert ER. Chronic stress, epigenetics, and adipose tissue metabolism in the obese state. Nutr Metab (Lond) 2020; $17: 88$.

54. Farkhondeh T, Llorens S, Pourbagher-Shahri AM, Ashrafizadeh M, Talebi $\mathrm{M}$, Shakibaei M, et al. An overview of the role of adipokines in cardiometabolic diseases. Molecules 2020;25:5218.

55. Jung UJ, Choi MS. Obesity and its metabolic complications: the role of adipokines and the relationship between obesity, inflammation, insulin resistance, dyslipidemia and nonalcoholic fatty liver disease. Int J Mol Sci 2014;15:6184-223.

56. Kazmi A, Sattar A, Hashim R, Khan SP, Younus M, Khan FA. Serum leptin values in the healthy obese and non-obese subjects of Rawalpindi. J Pak Med Assoc 2013;63:245-8.

57. Mao S, Fang L, Liu F, Jiang S, Wu L, Zhang J. Leptin and chronic kidney diseases. J Recept Signal Transduct Res 2018;38:89-94.

58. Nielsen R, Christensen EI, Birn H. Megalin and cubilin in proximal tubule protein reabsorption: from experimental models to human disease. Kidney Int 2016;89:58-67.

59. Wolf G, Ziyadeh FN. Leptin and renal fibrosis. Contrib Nephrol 2006; 151:175-83.

60. Lee MP, Orlov D, Sweeney G. Leptin induces rat glomerular mesangial cell hypertrophy, but does not regulate hyperplasia or apoptosis. Int J Obes 2005;29:1395-401.

61. Noor S, Alam F, Fatima SS, Khan M, Rehman R. Role of leptin and dyslipidemia in chronic kidney disease. Pak J Pharm Sci 2018;31:893-97.

62. Liu B, Qiao J, Hu J, Fan M, Zhao Y, Su H, et al. Leptin promotes endothelial dysfunction in chronic kidney disease by modulating the MTA1-mediated WNT/B-catenin pathway. Mol Cell Biochem 2020;473:155-66.

63. Esfahani M, Movahedian A, Baranchi M, Goodarzi MT. Adiponectin: an adipokine with protective features against metabolic syndrome. Iran J Basic Med Sci 2015; 18:430-42.

64. Ayina CN, Noubiap JJ, Etoundi Ngoa LS, Boudou P, Gautier JF, Mengnjo MK, et al. Association of serum leptin and adiponectin with anthropomorphic indices of obesity, blood lipids and insulin resistance in a SubSaharan African population. Lipids Health Dis 2016;15:96.

65. Jing Y, Jin S, Qiao R, Fang J. Association of adipocytokines with obesity and insulin resistance in Korean-Chinese and Han nationality pupils of Yanbian area. Wei Sheng Yan Jiu 2015;44:581-5.

66. Kuo IC, Wu PH, Lin HY, Niu SW, Huang JC, Hung CC, et al. The association of adiponectin with metabolic syndrome and clinical outcome in patients with non-diabetic chronic kidney disease. PLoS One 2019;14: e0220158.

67. Pabalan N, Tiongco RE, Pandac JK, Paragas NA, Lasta SL, Gallego N, et al. Association and biomarker potential of elevated serum adiponectin with nephropathy among type 1 and type 2 diabetics: a meta-analysis. PLoS One 2018;13:e0208905.

68. Choi SR, Lim JH, Kim MY, Kim EN, Kim Y, Choi BS, et al. Adiponectin receptor agonist AdipoRon decreased ceramide, and lipotoxicity, and ameliorated diabetic nephropathy. Metabolism 2018;85:348-60.

69. Song SH, Oh TR, Choi HS, Kim CS, Ma SK, Oh KH, et al. High serum adiponectin as a biomarker of renal dysfunction: Results from the KNOWCKD study. Sci Rep 2020;10:5598.

70. de Vries AP, Ruggenenti P, Ruan XZ, Praga M, Cruzado JM, Bajema IM, et al. Fatty kidney: emerging role of ectopic lipid in obesity-related renal disease. Lancet Diabetes Endocrinol 2014;2:417-26.

71. Li Z, Woollard JR, Wang S, Korsmo MJ, Ebrahimi B, Grande JP, et al. Increased glomerular filtration rate in early metabolic syndrome is associated with renal adiposity and microvascular proliferation. Am J Physiol Renal Physiol 2011;301:F1078-87.

72. Verani RR. Obesity-associated focal segmental glomerulosclerosis: pathological features of the lesion and relationship with cardiomegaly and hyperlipidemia. Am J Kidney Dis 1992;20:629-34.

73. Gai Z, Wang T, Visentin M, Kullak-Ublick GA, Fu X, Wang Z. Lipid accumulation and chronic kidney disease. Nutrients 2019;11:722.

74. Adeosun SO, Gordon DM, Weeks MF, Moore KH, Hall JE, Hinds TD 
$\mathrm{Jr}$, et al. Loss of biliverdin reductase-A promotes lipid accumulation and lipotoxicity in mouse proximal tubule cells. Am J Physiol Renal Physiol 2018;315:F323-31.

75. Barker DJ, Winter PD, Osmond C, Margetts B, Simmonds SJ. Weight in infancy and death from ischaemic heart disease. Lancet 1989;2:577-80.

76. Mohseni R, Mohammed SH, Safabakhsh M, Mohseni F, Monfared ZS, Seyyedi J, et al. Birth weight and risk of cardiovascular disease incidence in adulthood: a dose-response meta-analysis. Curr Atheroscler Rep 2020; 22:12.

77. Knop MR, Geng TT, Gorny AW, Ding R, Li C, Ley SH, et al. Birth weight and risk of type 2 diabetes mellitus, cardiovascular disease, and hypertension in adults: a meta-analysis of 7646267 participants from 135 studies. J Am Heart Assoc 2018;7:e008870.

78. Starr MC, Hingorani SR. Prematurity and future kidney health: the growing risk of chronic kidney disease. Curr Opin Pediatr 2018;30:228-35.

79. Elshenawy S, Simmons R. Maternal obesity and prenatal programming. Mol Cell Endocrinol 2016;435:2-6.

80. Glastras SJ, Chen H, McGrath RT, Zaky AA, Gill AJ, Pollock CA, et al. Effect of GLP-1 receptor activation on offspring kidney health in a rat model of maternal obesity. Sci Rep 2016;6:23525.

81. Glastras SJ, Tsang M, Teh R, Chen H, McGrath RT, Zaky AA, et al. Maternal obesity promotes diabetic nephropathy in rodent offspring. Sci Rep 2016;6:27769.

82. Glastras SJ, Chen H, Tsang M, Teh R, McGrath RT, Zaky A, et al. The renal consequences of maternal obesity in offspring are overwhelmed by postnatal high fat diet. PLoS One 2017;12:e0172644.

82. Lu J, Zhang S, Li W, Leng J, Wang L, Liu H, et al. Maternal gestational diabetes is associated with offspring's hypertension. Am J Hypertens 2019; 32:335-42.

83. Hsu CW, Yamamoto KT, Henry RK, De Roos AJ, Flynn JT. Prenatal risk factors for childhood CKD. J Am Soc Nephrol 2014;25:2105-11.

84. Glastras SJ, Chen H, Pollock CA, Saad S. Maternal obesity increases the risk of metabolic disease and impacts renal health in offspring. Biosci Rep 2018;38:BSR20180050.

85. Wong MG, The NL, Glastras S. Maternal obesity and offspring risk of chronic kidney disease. Nephrology 2018;23 Suppl 4:84-7.

86. Yim HE, Yoo KH. Early life obesity and chronic kidney disease in later life. Pediatr Nephrol 2015;30:1255-63.

87. Tain YL, Hsu CN. Developmental origins of chronic kidney disease: should we focus on early Life? Int J Mol Sci 2017;18:381.

88. Nehus E, Mitsnefes M. Childhood obesity and the metabolic syndrome. Pediatr Clin North Am 2019;66:31-43.

89. Look AHEAD Research Group. Effect of a long-term behavioural weight loss intervention on nephropathy in overweight or obese adults with type 2 diabetes: a secondary analysis of the Look AHEAD randomised clinical trial. Lancet Diabetes Endocrinol 2014;2:801-9.
90. Bolignano D, Zoccali C. Effects of weight loss on renal function in obese CKD patients: a systematic review. Nephrol Dial Transplant 2013;28 Suppl 4:iv82-98.

91. Zelle DM, Klaassen G, van Adrichem E, Bakker SJ, Corpeleijn E, Navis G. Physical inactivity: a risk factor and target for intervention in renal care. Nat Rev Nephrol 2017;13:152-68.

92. Mallamaci F, Ruggenenti P, Perna A, Leonardis D, Tripepi R, Tripepi G, et al. ACE inhibition is renoprotective among obese patients with proteinuria. J Am Soc Nephrol 2011;22:1122-8.

93. Wanner C, Tonelli M, Kidney Disease: Improving Global Outcomes Lipid Guideline Development Work Group Members. KDIGO clinical practice guideline for lipid management in CKD: summary of recommendation statements and clinical approach to the patient. Kidney Int 2014;85:13039.

94. Expert Panel on Integrated Guidelines for Cardiovascular Health and Risk Reduction in Children and Adolescents, National Heart, Lung, and Blood Institute. Expert panel on integrated guidelines for cardiovascular health and risk reduction in children and adolescents: summary report. Pediatrics 2011;128(Suppl 5):S213-56.

95. Imam TH, Fischer H, Jing B, Burchette R, Henry S, DeRose SF, et al. Estimated GFR before and after bariatric surgery in CKD. Am J Kidney Dis 2017;69:380-8.

96. Chang AR, Chen Y, Still C, Wood GC, Kirchner HL, Lewis M, et al. Bariatric surgery is associated with improvement in kidney outcomes. Kidney Int 2016;90:164-71.

97. Pratt JS, Lenders CM, Dionne EA, Hoppin AG, Hsu GL, Inge TH, et al. Best practice updates for pediatric/adolescent weight loss surgery. Obesity 2009;17:901-10.

98. Nehus EJ, Khoury JC, Inge TH, Xiao N, Jenkins TM, Moxey-Mims $\mathrm{MM}$, et al. Kidney outcomes three years after bariatric surgery in severely obese adolescents. Kidney Int 2017;91:451-58.

99. Bjornstad P, Nehus E, van Raalte D. Bariatric surgery and kidney disease outcomes in severely obese youth. Semin Pediatr Surg 2020;29:150883.

100. Srivastava G, Apovian CM. Current pharmacotherapy for obesity. Nat Rev Endocrinol 2018;14:12-24

101. Woodard K, Louque L, Hsia DS. Medications for the treatment of obesity in adolescents. Ther Adv Endocrinol Metab 2020;11:2042018820918789.

102. Pilitsi E, Farr OM, Polyzos SA, Perakakis N, Nolen-Doerr E, Papathanasiou AE, et al. Pharmacotherapy of obesity: available medications and drugs under investigation. Metabolism 2019;92:170-92.

How to cite this article: Yim HE, KH Yoo. Obesity and chronic kidney disease: prevalence, mechanism, and management. Clin Exp Pediatr 2021;63:511-5. https://doi.org/10.3345/ cep.2021.00108 